\title{
Effect of Carburizing and Shot Peening on the Microstructure and Surface Properties of 17-CrNi6-Mo Steel
}

\author{
Y. H. Lv, ${ }^{\text {a,b,c }}$ D. Y. Gai, ${ }^{a, b, c, 1}$ Y. Q. Song, ${ }^{d}$ and X. Q. Ma ${ }^{a}$ \\ ${ }^{a}$ College of Material Science and Chemical Engineering, Harbin Engineering University, Harbin, \\ China \\ ${ }^{\mathrm{b}}$ Key Laboratory of Superlight Material and Surface Technology, Ministry of Education, Harbin \\ Engineering University, Harbin, China \\ c Institute of Surface/Interface Science and Technology, Harbin Engineering University, Harbin, \\ China \\ ${ }^{\mathrm{d}}$ Harbin Electric Power Equipment Co, Ltd., Harbin, China \\ ${ }^{1}$ gaidengyu@hrbeu.edu.cn
}

Carburizing and shot peening are commonly accepted surface treatment methods used to improve the surface properties of materials. Researchers are making attempts to optimize their application for obtaining superior mechanical properties. However, there are few comprehensive reports on this problem. The combination of carburizing and shot peening is used for the surface treatment of 17-CrNi6-Mo steel. This is followed by detailed analysis employing optical and scanning electron microscopy, microhardness testing, surface roughness measurements, and the measurement of residual stresses using $X$-ray diffraction. The results show that shot peening can further improve the microstructure and surface properties of carburized specimens since it induced the phase transformation of a carburized layer. Moreover, simulation of the phase composition variation curve along with the change in the carbon content and the continuous cooling transformation (CCT) curve of the specimen is also presented. The results are used to elucidate the carburizing effect on a 17-CrNi6-Mo steel surface microstructure.

Keywords: shot peening, carburizing, microstructure, microhardness, residual stress, X-ray diffraction.

Introduction. 17-CrNi6-Mo steel, due to its high strength, ductility and hardenability, is mainly used to manufacture heavy-duty gears, which are widely used in industry [1-3]. In general, these industrial components have higher requirements on the surface quality in production, and majority of failures in engineering materials are very sensitive to the structure and properties of the surface and can attributed to fatigue fracture, fretting fatigue, wear and corrosion [4-6]. In order to satisfy the industrial demand, several studies have been reported on the improvement of the 17-CrNi6-Mo steel surface properties by carburizing and shot peening (SP).

Carburizing is a hardening process whereby carbon is introduced into the surface of low-carbon or low-alloy steel by holding a single phase austenite region at the particular temperature. In this case, after quenching and low-temperature tempering, the surface layer attains higher values of carbon content, hardness, and wear resistance, but the core of the component is still a low-carbon steel having good toughness and plasticity [7-10]. The SP is a cold-working process, which is widely used in industry for the effective improvement of the mechanical properties of the component surface [11-15]. In the SP process, a stream of small hard balls with high speed impacts the treated surface of the parts and induces elastic and plastic deformations in the subsurface layers. The plastically deformed zone of the outer surface tends to expand while the elastic deformation zone inhibits this process in the neighboring subsurface. As a result, the component can obtain a compressive residual stress field in near surface layer [11, 16-19]. 
At present, a considerable amount of literature about improving the surface performance of 17-CrNi6-Mo steel is available where either carburizing or SP has been used in isolation. As described above, the two processes used together can effectively improve the surface performance of 17-CrNi6-Mo steel. However, the effect of their combination has not been investigated. In this paper, carburizing of 17-CrNi6-Mo steel followed by SP was investigated in detail. Carburizing and SP have been performed on steel specimens. The treated specimens have been characterized by optical microscopy (OM) and scanning electron microscopy (SEM) observation, residual stress analysis using X-ray diffraction (XRD), microhardness tests and surface roughness measurement. The microstructure and surface layer properties of 17-CrNi6-Mo steel under different sets of combination of these twin processes have been discussed in detail.

\section{Materials and Methods.}

1.1. Material. The material used in this study is $17-\mathrm{CrNi6}-\mathrm{Mo}$ steel having a chemical composition of $0.17 \mathrm{C}, \geq 0.40 \mathrm{Si}, 0.50 \mathrm{Mn}, 1.65 \mathrm{Cr}, 1.60 \mathrm{Ni}, 0.30 \mathrm{Mo}, \geq 0.03 \mathrm{Cu}, \geq 0.035 \mathrm{~S}$, $\geq 0.035 \mathrm{P}, \mathrm{Fe}-$ balance (all in wt.\%). The material was cut into small specimens with the geometry of $50 \times 50 \times 30 \mathrm{~mm}$ by wire-electrode cutting method. Before carburizing and SP treatment, specimen surface was ground from 180 to 1200 grit sandpapers and polished with chromic oxide. Soon afterwards carburizing and SP was carried out on the surface, respectively.

1.2. Heat Treatment. The carburizing of $17-\mathrm{CrNi} 6-\mathrm{Mo}$ steel was carried out in the pit furnace, and the carbon potential was $1.15 \pm 0.05$ and $0.7 \pm 0.05 \mathrm{wt} . \%$ which was controlled by computer automatic control system of oxygen probe. Specimen was heated at $920^{\circ} \mathrm{C}$, held at the temperature for $40 \mathrm{~h}$ and air-cooled. Meanwhile, the carburizing process was divided into two stages, the active carburizing stage with $25 \mathrm{~h} / 1.15 \pm 0.05$ wt.\% and the diffusion stage with $15 \mathrm{~h} / 0.7 \pm 0.05 \mathrm{wt} . \%$, respectively. After the carburizing, the specimens were heated at $830^{\circ} \mathrm{C}$ for $4 \mathrm{~h}$ followed by salt bath quenching and finally tempered at $210^{\circ} \mathrm{C}$ for $12 \mathrm{~h}$ followed by air-cooling. Moreover microstructure grade of the specimen is shown in Table 1.

$\mathrm{T}$ a $\mathrm{b} 1 \mathrm{e} 1$

Microstructure Grade and Hardness of Specimens after Heat Treatment

\begin{tabular}{|c|c|c|c|c|c|c|}
\hline Specimen & $\begin{array}{c}\text { Case depth } \\
(\mathrm{mm})\end{array}$ & $\begin{array}{c}\text { Martensite } \\
\text { and retained } \\
\text { austenite } \\
\text { (Grade) }\end{array}$ & $\begin{array}{c}\text { Carbide } \\
\text { (Grade) }\end{array}$ & $\begin{array}{c}\text { Ferrite } \\
\text { (Grade) }\end{array}$ & $\begin{array}{c}\text { Surface } \\
\text { hardness } \\
\text { (HRC) }\end{array}$ & $\begin{array}{c}\text { Core } \\
\text { hardness } \\
\text { (HRC) }\end{array}$ \\
\hline C1-C6 & 1.27 & 3 & $4-5$ & 1 & $58-60$ & $38-42$ \\
\hline
\end{tabular}

1.3. Shot Peening Treatment. The carburised specimens were subjected to SP treatment by air blast SP equipment. The SP intensity was tested by the arc height of Almen strips (A). A lot of SP parameters control the SP intensity, including jet pressure of nozzle, SP time, the diameter of the nozzle, the average ball diameter, the distance between nozzle and specimens, coverage, etc. [20]. In this study, the selected parameters were that the diameter of the nozzle was $10 \mathrm{~mm}$, the distance between nozzle and specimens was $30 \mathrm{~mm}$, the coverage was $200 \%$. The balls were cast steel balls with $0.8 \mathrm{~mm}$ average diameter, and the hardness value was $53 \mathrm{HRC}$. The SP treatment adopted the intensity of $0.2,0.3,0.4$, 0.5 , and $0.6 \mathrm{mmA}$, respectively. Finally, the balls impacted perpendicularly on specimen surface.

1.4. Measurement of Microstructural and Residual Stress. After SP treatment, specimens were cut into the geometry of $10 \times 10 \times 10 \mathrm{~mm}$ by wire-electrode cutting method. Before the observation of the OM and SEM, specimens were ground from 180 to 1200 grit 
sandpapers and polished with chromic oxide, subsequently etched by $5 \%$ Nital. The Vickers microhardness was measured at the load of $0.98 \mathrm{~N}$ by HVS-1000 microhardness tester, loading for $10 \mathrm{~s}$.

XRD patterns were measured by X'Pert PRO diffractometer $(\mathrm{Cu}-\mathrm{K} \alpha$ radiation, $\lambda=1.54056 \AA$ ). The voltage, current, and scanning angle were $40 \mathrm{kV}, 40 \mathrm{~mA}$ and $20-140^{\circ}$, respectively. The residual stress was measured by using X'Pert PRO X-ray stress analyzer with $\mathrm{Cu}-\mathrm{K} \alpha$ radiation (voltage $40 \mathrm{kV}$, current $4 \mathrm{~mA}$ ), and the electropolishing device was selected to remove the thin surface layer by Proto Electrolytic Polisher Model 8818. The martensite (211) peaks were measured and then the residual stress was determined by the $\sin ^{2} \psi$ method [1].

\section{Results and Discussion.}

2.1. Microstructural. The cross section OM observation was performed using Axiovert 200 MAT OM. Overall view of the OM observation shown in Fig. 1, the carburizing layer structure is obviously refined, and the deformed area is produced on the top surface. With the increase of SP intensity, the deformation area is larger and more evident.

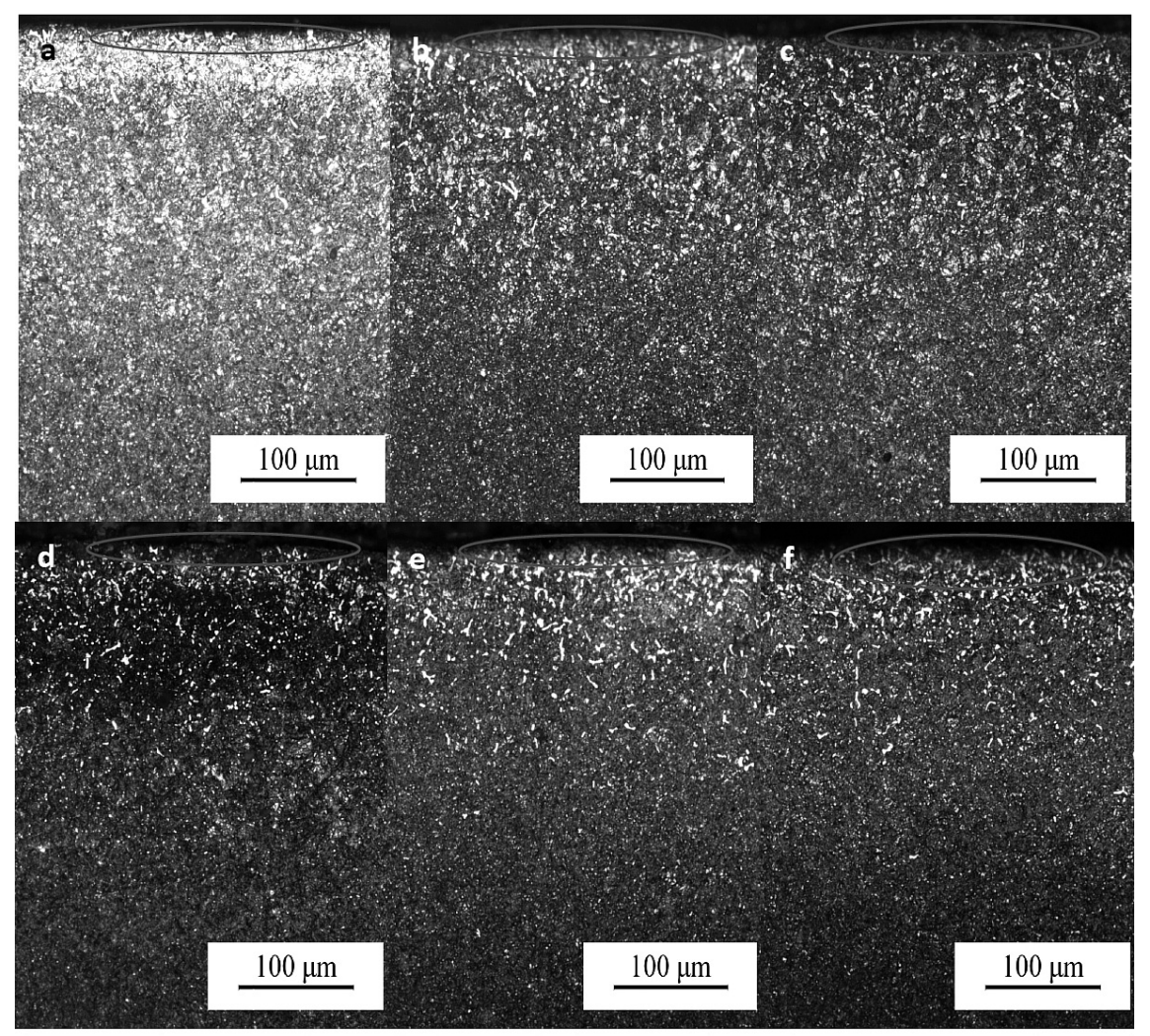

Fig. 1. The cross section observation of OM before and after SP treatment, the red tagged area shows elastic and plastic deformation zones: (a) not SP; (b) SP with $0.2 \mathrm{mmA}$; (c) SP with $0.3 \mathrm{mmA}$; (d) SP with $0.4 \mathrm{mmA}$; (e) $\mathrm{SP}$ with $0.5 \mathrm{mmA}$; (f) $\mathrm{SP}$ with $0.6 \mathrm{mmA}$.

Based on the definitions of JB/T 6141.3-1992, the SEM observation of the top surface was measured by EVO 18 SEM, shown in Fig. 2. It indicates that the surface grain is refined, and the non-martensite phase is reduced. The result is consistent with the analysis of XRD patterns, which will be illustrated in the following section. Moreover, the degree of grain refinement is more obvious with the increase of SP intensity. The observation under SEM with high power is shown in Fig. 3. It can be seen from the diagram that the SP with 


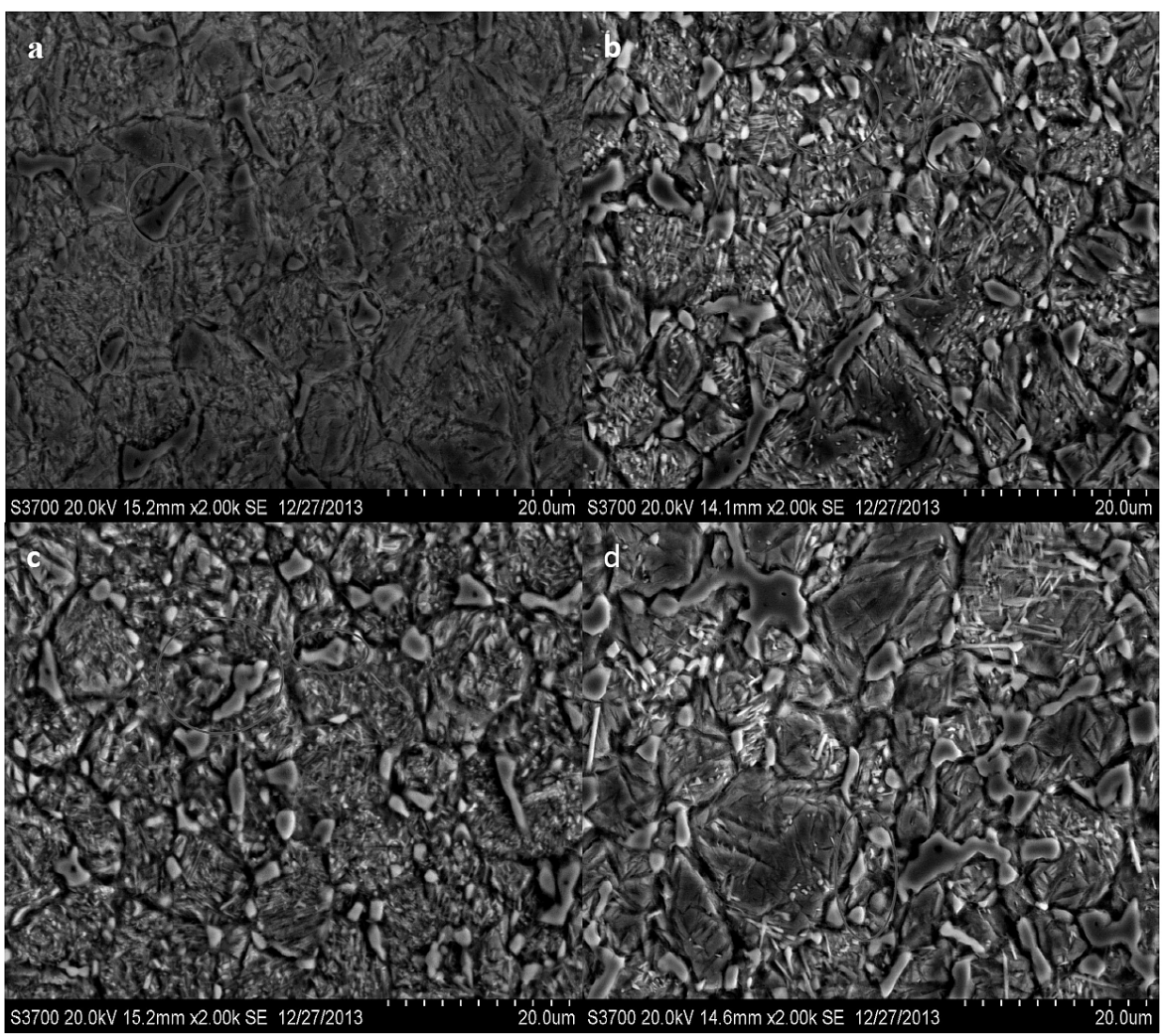

Fig. 2. The SEM observation of the top surface before and after SP treatment, the red tagged area shows non-martensitic phase: (a) not SP; (b) SP with $0.2 \mathrm{mmA}$; (c) SP with $0.3 \mathrm{mmA}$; (d) SP with $0.4 \mathrm{mmA}$.

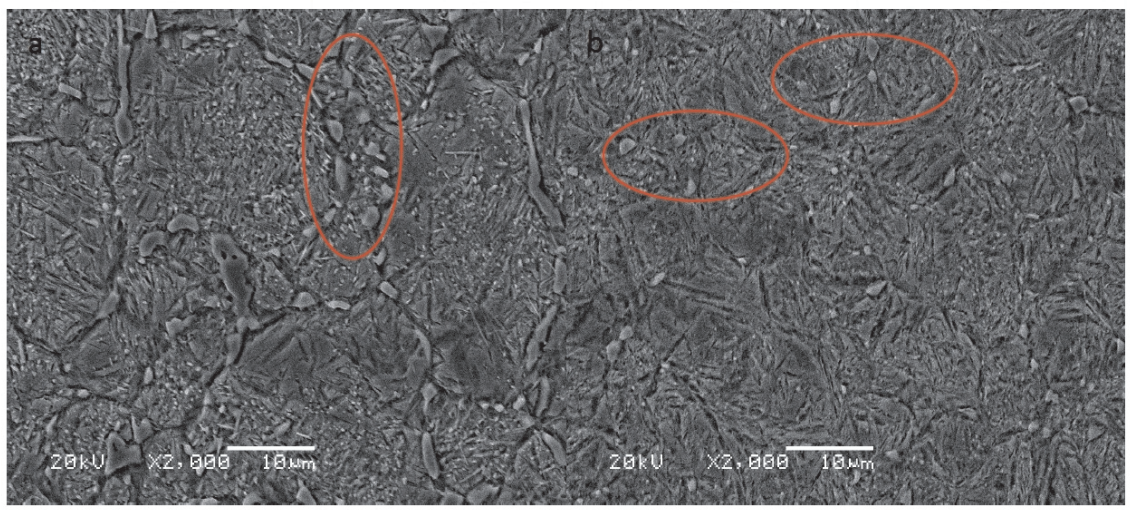

Fig. 3. The observation with high power of SEM, the red tagged shows non-martensitic phase: (a) SP with $0.5 \mathrm{mmA}$; (b) SP with $0.6 \mathrm{mmA}$.

$0.6 \mathrm{mmA}$ can further refine grain, and the non-martensite structure is more completely absent from the grain boundaries.

2.2. Simulation of Continuous Cooling Transformation (CCT). In order to explain the effect of carburizing treatment on the structure, we simulated the variation curve of phase fraction along with the carburizing layer depth and the CCT curve of specimen by Jmat-Pro software. Jmat-Pro was the material performance simulation software by Sente Software Company. The steel database was selected to simulate the variation curve of phase 
fraction and CCT. The results of computer simulations are shown in Figs. 4 and 5. As is shown in Fig. 4, specimens heated at $830^{\circ} \mathrm{C}$ are not completely austenitized above $1.14 \mathrm{~mm}$, owing to the different of carbon content in carburizing layer. The group of carburizing specimen includes austenite, $\mathrm{M}_{23} \mathrm{C}_{6}$, and cementite during $0.09-0.54 \mathrm{~mm}$ of specimen surface. It is accepted that the carbon content of the austenite grain boundaries is higher than the carbon content within the grains. The grain boundaries provide nucleation sites for carbide formation during the carburizing process. Hence, the carbide particles existed in the specimen surface before quenching, owing to the increase of the carbon content in specimens surface.

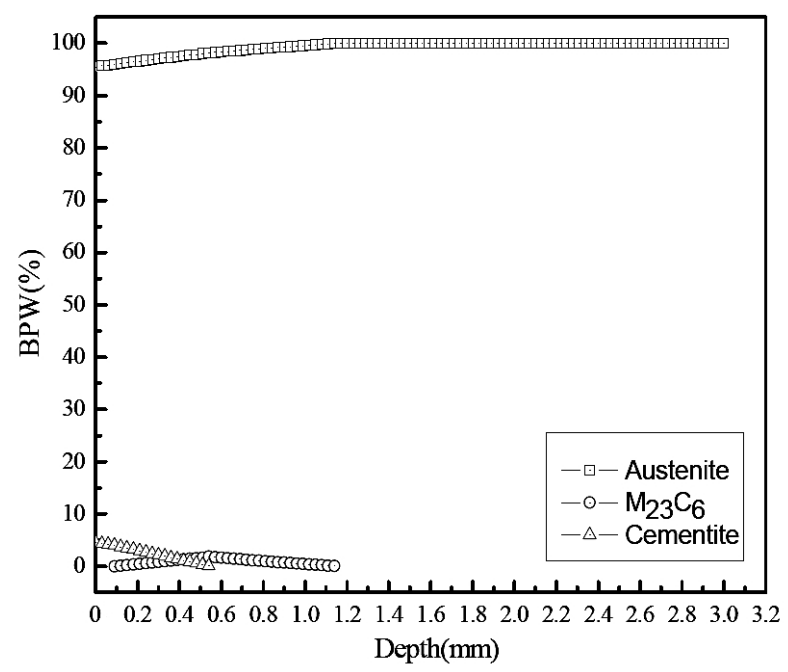

Fig. 4. The plot shows the variation of phase fraction as obtained by Jmat-Pro software at $830^{\circ} \mathrm{C}$.

Figure 5 shows the CCT of specimen before and after carburizing. It is accepted that the martensite transformation start point $\left(M_{s}\right)$ falls with an increase of carbon content in the material. By comparison with the CCT before and after carburizing, it can be clearly seen that the $M_{s}$ of the carburizing layer is lower. In other words, the different $M_{s}$ in surface and substrate cause the variation of material properties after quenching. In addition, the retained austenite of carburizing layer is more than the substrate. The result is consistent with the inspection report of carburizing specimens.

2.3. Microhardness. The microhardness distribution curve after SP treatment is shown in Fig. 6. It can be seen from the diagram, although the specimens experience different SP treatment process, the overall trend of hardness distribution curves is consistent. The hardness becomes smaller along the layer depth, and the curve is the steep drop to $2000 \mu \mathrm{m}$ depth. A comparison of hardness distribution curve shows that the hardness increases with the increase of SP intensity. Hence, under the SP intensity $0.6 \mathrm{mmA}$, the surface after SP treatment has the maximum hardness that is $911.9 \mathrm{HV}$. The hardness of the substrate is $427.91 \mathrm{HV}$, and the hardness of not shot peening (NSP) treatment specimens which underwent carburizing and quenching treatment is $808.06 \mathrm{HV}$ on the surface. After the SP treatment, the hardness increased by $13 \%$ as compared to the NSP specimens and by $113 \%$ compared to the substrate (17-CrNi6-Mo). In substrate itself, the hardness after carburizing and quenching treatment is increased by $89 \%$. It shows that SP treatment can further improve the hardness. Moreover, it has been observed by OM and SEM microscopy that the plastic deformation occurs only on the surface layer, and the grain sizes are finer after the SP treatment. As is known to all, the grain size and dislocation density have significant effect on the hardness of materials. 


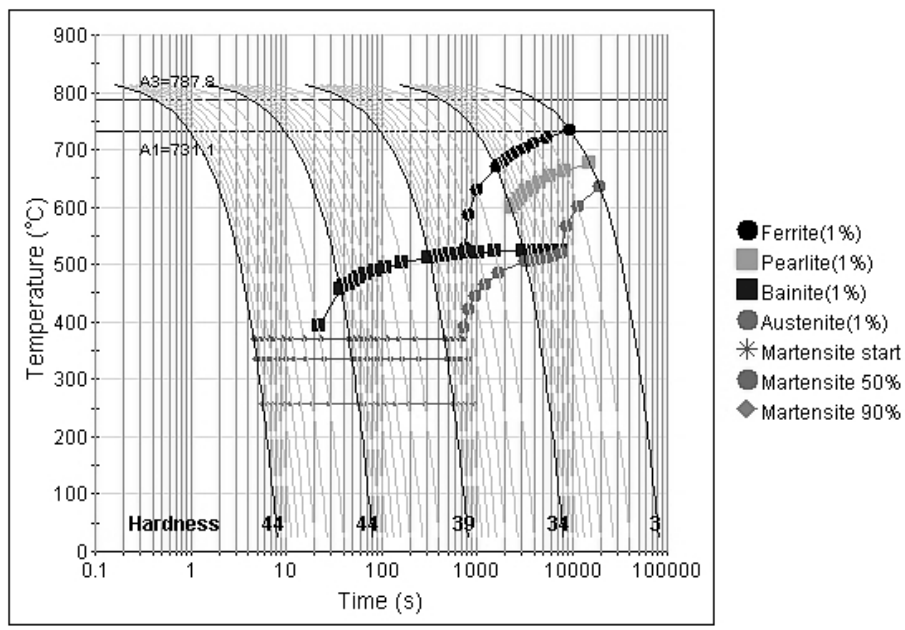

Austenitisation temperature $\left({ }^{\circ} \mathrm{C}\right): \mathbf{8 3 0 . 0}$ Grain size : 9.0 ASTM

a

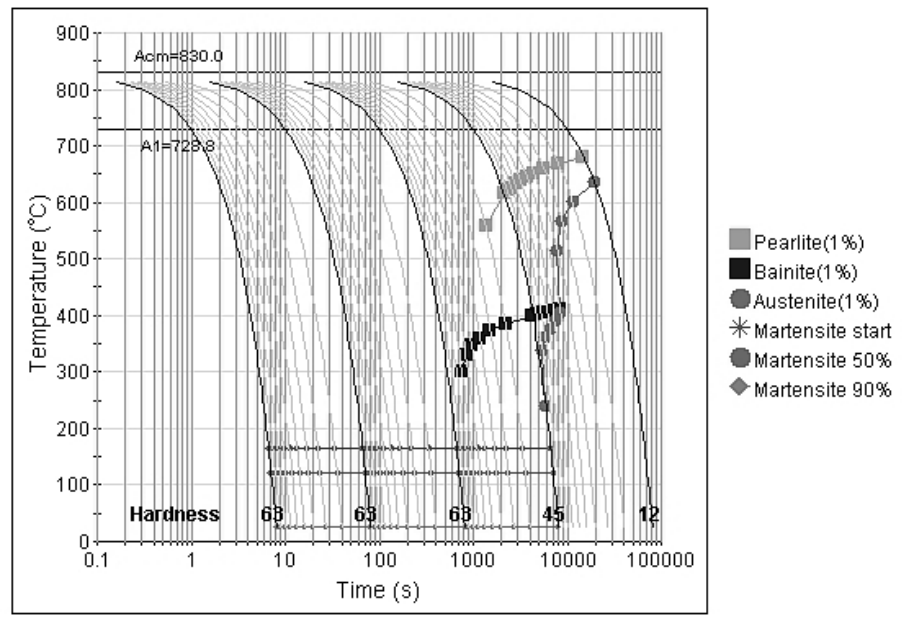

Austenitisation temperature $\left({ }^{\circ} \mathrm{C}\right): \mathbf{8 3 0 . 0}$ Grain size : 9.0 ASTM

b

Fig. 5. CCT of specimens before and after carburizing: (a) before carburizing; (b) CCT of specimen surface after carburizing.

2.4. Surface Roughness. After low intensity SP treatment, the surface appears smooth. However, with the increase of SP intensity, the specimen surface becomes rougher and the ball pit is deeper. Table 2 shows the surface roughness parameters of SP specimen by 2205 type roughness measuring instrument. Values of $R a$ and $R z$ are most often considered as the representative parameter of surface roughness [4]. Based on the definitions of ISO 4287 [21], $R a$ represents the arithmetic-mean value, and $R z$ represents the maximum height of the profile. The $R a$ and $R z$ values were raised by SP treatment. Although, the $R a$ value of $0.5 \mathrm{mmA}$ intensity is more than the $R a$ value of $0.6 \mathrm{mmA}$ intensity, the $R z$ value of $0.6 \mathrm{mmA}$ is more than the $R z$ value of $0.5 \mathrm{mmA}$ intensity. Overall, the $R a$ and $R z$ values also increased with the increase of SP intensity. The optical microscopy (Fig. 1) exhibits the formation of the rough surface. The deformation area is more evident with the increase of SP intensity. 
T a b 1 e 2

Surface Roughness of the Specimen under Different SP Treatment

\begin{tabular}{||c|c|c|c|c|c||}
\hline \multirow{2}{*}{ Material } & \multicolumn{5}{|c||}{ Surface roughness $R a / R z(\mu \mathrm{m})$} \\
\cline { 2 - 6 } & $0.2 \mathrm{mmA}$ & $0.3 \mathrm{mmA}$ & $0.4 \mathrm{mmA}$ & $0.5 \mathrm{mmA}$ & $0.6 \mathrm{mmA}$ \\
\hline 17-CrNi6-Mo & $0.679 / 1.014$ & $0.726 / 0.646$ & $1.193 / 0.649$ & $1.543 / 1.743$ & $1.512 / 2.464$ \\
\hline
\end{tabular}
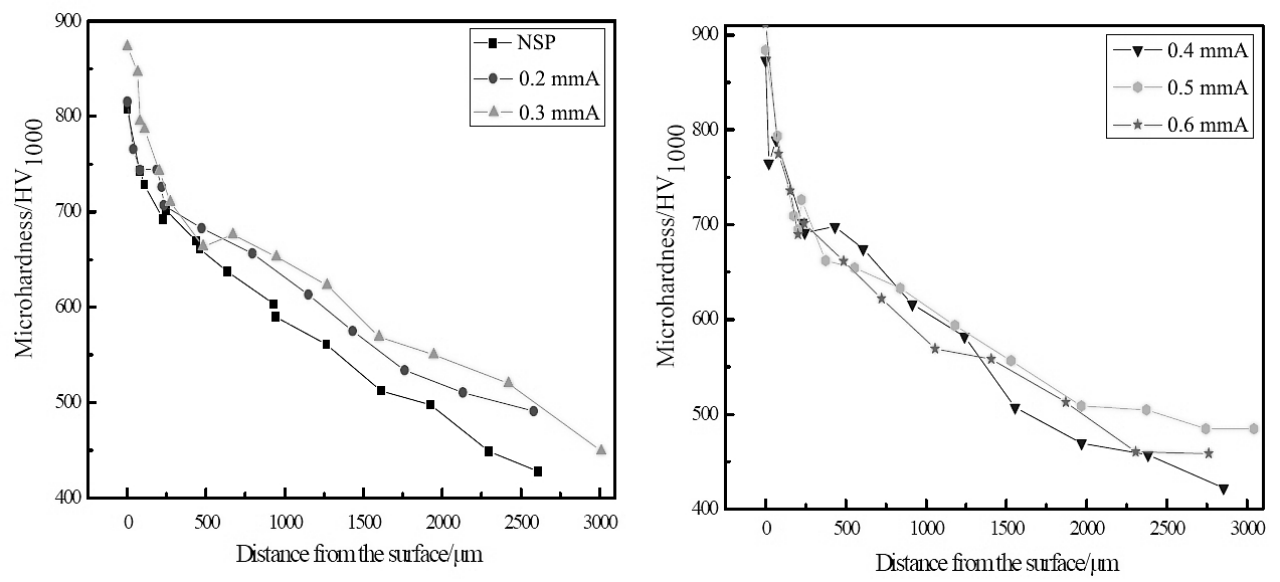

Fig. 6. The microhardness distribution curve along the layer depth.

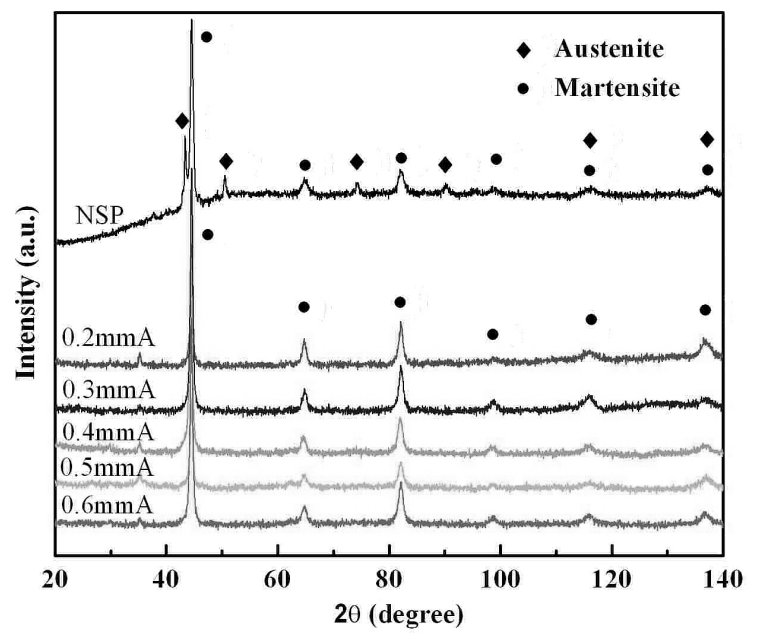

Fig. 7. X-ray diffraction pattern of the specimen under different conditions of SP treatment.

2.5. X-Ray Diffraction. The XRD patterns of the top surface are shown in Fig. 7. As shown in the figure, the NSP specimen has martensite and austenite phase. Compared with the NSP specimen, the SP specimens only have martensite phase. It shows that the non-martensite of NSP specimens contains austenite, and the retained austenite content of the surface area is reduced by SP treatment. It is mainly due to the stress induces martensitc phase transformation, which is produced by the SP treatment. In this work, after the SP intensity of $0.2 \mathrm{mmA}$, the retained austenite entirely disappeared in the near surface region. The nature of XRD peak does not undergo any change, but the XRD patterns have the tend to be broaden with the increase of SP intensity. 
The full width at half maximum (FWHM) is a parameter that is usually presumed as a level of hardening for the hardening material and is related to the microstrain [4, 22, 23]. In order to study the FWHM distribution along the layer depth, electropolishing is used to remove the damage of SP treatment surface. Figure 8 shows the FWHM distribution curve along the layer depth after electorpolishing. The values of FWHM are raised with the increase of SP intensity. Compared with the NSP specimen, the FWHM value is 0.666 degree at the condition of SP intensity $0.6 \mathrm{mmA}$, which is increased $11.8 \%$ than the NSP specimen. And, the trend of the FWHM change is consistent with the test result of the hardness (increase 13\%).

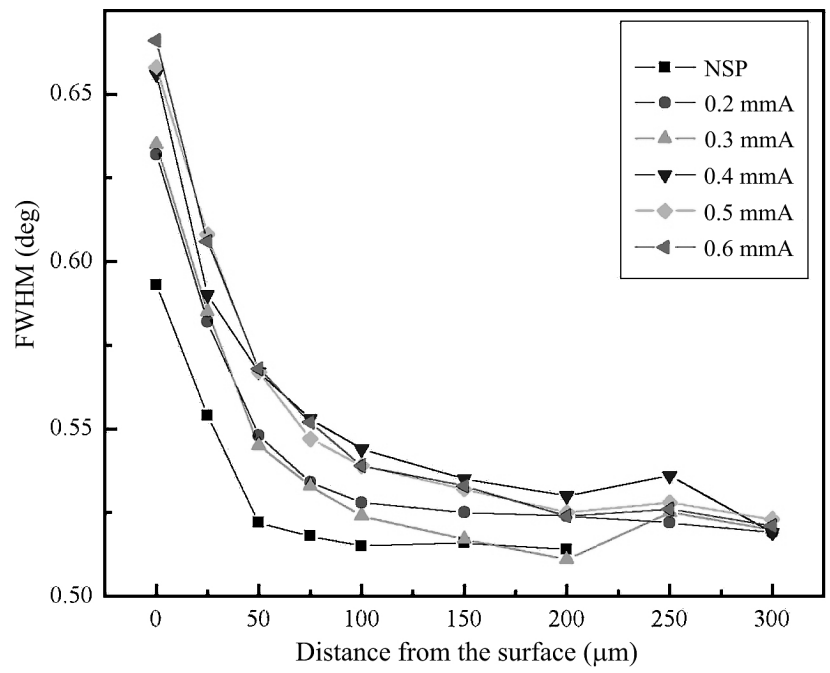

Fig. 8. FWHM distribution along the layer depth.

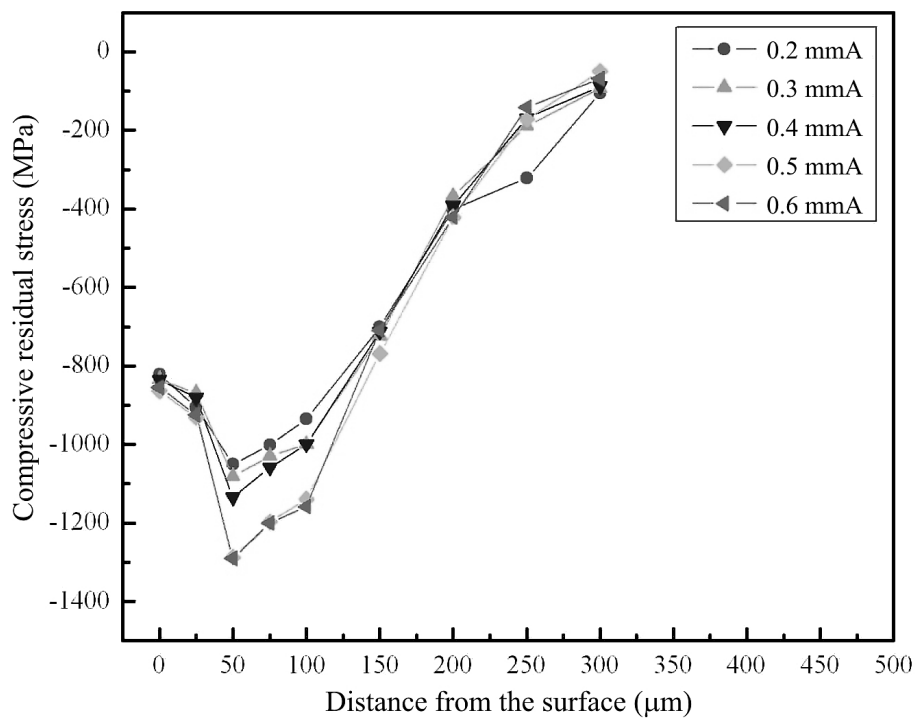

Fig. 9. Residual stress distribution curve of SP specimens.

2.6. Residual Stress. Figure 9 shows the residual stress distribution curve along the layer depth. It can be seen from the diagram that the compressive residual stress (CRS) is produced in all specimen surface. Because of the ball impacted the surface of the parts, the 
elastic and plastic deformation was produced in near surface layer. And the elastic deformation zone inhibited the plastic deformation zone to expand. Hence, the parts can obtain a compressive residual stress field in near surface layer. Moreover, the CRS value of the top surface has the whole trend to increase with the increase of SP intensity. Moreover, the CRS value is first increased to the maximum $(\max )$, and with the increase of the layer depth gradually smaller. In other words, the max CRS value is not in the top surface, but in the subsurface. The max CRS value of SP with $0.6 \mathrm{mmA}$ is $-1290 \mathrm{MPa}$. Through further analysis of the experimental data, it can be drawn that the position of the max CRS is around $50 \mu \mathrm{m}$ of carburizing layer, but the depth of CRS field is different. As is shown in figure, the rate of CRS value decline with larger SP intensity is faster in the range from 50 to $200 \mu \mathrm{m}$, contrarily, the rate of CRS value decline with larger SP intensity is slower after $200 \mu \mathrm{m}$. That is to say that the larger CRS field will be produced by the severe SP treatment. However, in production practice, there are two ways that are selected to determine whether over peening. One is based on the change of residual stress, or the other is based on the microcracks of component surface. Hence, the surface CRS value of SP with $0.6 \mathrm{mmA}$ is lower than the surface CRS value of SP with $0.5 \mathrm{mmA}$, it illustrates that the SP with $0.6 \mathrm{mmA}$ induces over peening.

Conclusions. In order to investigate the effect of the combined carburizing and SP application, SP has been applied on the pre-carburized surface. The effect of their combination on the structure and properties of treated specimens has been examined through a variety of experimental technique and analysis, including the microstructure, CCT simulation, microhardness, CRS, etc. On the basis of the obtained results, the following conclusions can be drawn:

1. OM and SEM observations confirm that carburizing layer grain is refined after SP treatment, and the plastic deformation layer is produced on the surface of carburized specimens. With the increase of SP intensity, the degree of grain refinement is more obvious and the thickness of the compact layer becomes larger.

2. After SP treatment, microhardness of carburized layer, as compared to the substrate, increases by 113 and $13 \%$ more than that of the carburized surface. It demonstrates that SP can further improve the microhardness of 17-CrNi6-Mo steel after carburizing. The distribution curves of FWHM value are consistent with the microhardness distribution curve.

3. Although the SP intensity is different, the residual stress of specimen surface under their combination is CRS. Moreover, the location of the max CRS is around $50 \mu \mathrm{m}$. In addition, XRD patterns confirm that the retained austenite of treated specimens completely transforms to martensite. It is attributed to the stress induces martensite phase transformation.

4. The simulation result of CCT and the variation curve of phase fraction along with the carburizing layer depth confirm that the non-martensite has existed in carburizing layer before quenching. The Ms of carburizing layer is lower than the substrate, owing to the higher carbon content in carburizing layer. Meanwhile, the retained austenite is more than the substrate after heating treatment. Hence, SP after carburizing is crucial to further improve the properties of material surface.

Acknowledgments. The authors are grateful to the Harbin Electric Power Equipment Co. Ltd. for surface treatment and performing shot peening.

1. Peng $\mathrm{Fu}$ and Chuanhai Jiang, "Residual stress relaxation and micro-structural development of the surface layer of 18CrNiMo7-6 steel after shot peening during isothermal annealing," Mater. Des., 56, 1034-1038 (2014).

2. J. X. Liu, Z. J. He, and L. H. Wang, "Study on the durable factors of the grain size in 18CrNiMo7-6 by heating and cooling method," Adv. Mater. Res., 194-196, 228-231 (2011). 
3. J. Krawczyk, B. Pawlowski, and P. Bala, "Banded microstructure in forged 18CrNiMo7-6 steel," Metall. Foundry Eng., 35, 45-53 (2009).

4. S. M. Hassani-Gangaraj, A. Moridi, M. Guagliano, and A. Ghidini, "Nitriding duration reduction without sacrificing mechanical characteristics and fatigue behavior: The beneficial effect of surface nano-crystallization by prior severe shot peening," Mater. Des., 55, 492-498 (2014).

5. Sharidah Azuar Abdul Azis, Iswadi Jauhari, and Nor Wahida Ahamad, "Improving surface properties and wear behaviors of duplex stainless steel via pressure carburizing," Surf. Coat. Technol., 210, 142-150 (2012).

6. V. Azar, B. Hashemi, and Mahboobeh Rezaee Yazdi, "The effect of shot peening on fatigue and corrosion behavior of 316L stainless steel in Ringer's solution," Surf. Coat. Technol., 204, No. 21-22, 3546-3551 (2010).

7. Chengming Li, Qi He, Weizhong Tang, and Fanxiu Lu, "Carburising of steel AISI 1010 by using a cathode arc plasma process," Surf. Coat. Technol., 187, No. 1, 1-5 (2004).

8. J. M. Baek, Y. R. Cho, D. J. Kim, and K. H. Lee, "Plasma carburizing process for the low distortion of automobile gears," Surf. Coat. Technol., 131, No. 1-3, 568-573 (2000).

9. B. Edenhofer, W. Grafen, and J. M. Ziller, "Plasma-carburising a surface heat treatment process for the new century," Surf. Coat. Technol., 142-144, 225-234 (2001).

10. H. Jime'nez, M. H. Staia, and E. S. Puchi, "Mathematical modeling of a carburizing process of a SAE 8620H steel," Surf. Coat. Technol., 120-121, 358-365 (1999).

11. K. Zhan, C. H. Jiang and V. Ji, "Uniformity of residual stress distribution on the surface of S30432 austenitic stainless steel by different shot peening processes," Mater. Lett., 99, 61-64 (2013).

12. S. Tekeli, "Enhancement of fatigue strength of SAE 9245 steel by shot peening," Mater. Lett., 57, No. 3, 604-608 (2002).

13. J. D. Almer, J. B. Cohen, and B. Moran, "The effects of residual microstresses and microstresses on fatigue crack initiation," Mater. Sci. Eng., 284, No. 1-2, 268-279 (2000).

14. Zhou Wang, Chuanhai Jiang, Xiaoyan Gan, et al., "Influence of shot peening on the fatigue life of laser hardened 17-4PH steel," Int. J. Fatigue, 33, No. 4, 549-556 (2011).

15. H. P. Yang, X. C. Wu, Y. A. Min, et al., "Plasma boriding of high strength alloy steel with nanostructured surface layer at low temperature assisted by air blast shot peening," Surf. Coat. Technol., 228, 229-233 (2013).

16. Y. K. Gao, M. Yao and P. G. Shao, "Another mechanism for fatigue strength improvement of metallic parts by shot peening," J. Mater. Eng. Perform., 12, 507511 (2003).

17. Y. K. Gao and X. R. Wu, "Experimental investigation and fatigue life prediction for 7475-T7351 aluminum alloy with and without shot peening-induced residual stresses," Acta Mater., 59, No. 9, 3737-3747 (2011).

18. K. Mikova, S. Bagherifard, O. Bokuvka, and L. Trsko, "Fatigue behavior of X70 microalloyed steel after severe shot peenin," Int. J. Fatigue, 55, 33-42 (2013).

19. Wencai Liu, Guohua Wu, Chunquan Zhai, et al., "Grain refinement and fatigue strengthening mechanisms in as-extruded Mg-6Zn-0.5Gr and Mg-10Gd-3Y-0.5Zr magnesium alloys by shot peening," Int. J. Plasticity, 49, 16-35 (2013). 
20. Qiang Feng, Chuanhai Jiang, Zhou Xu, et al., "Effect of shot peening on the residual stress and microstructure of duplex stainless steel," Surf. Coat. Technol., 226, 140144 (2013).

21. ISO 4287. Geometrical Product Specifications (GPS)-Surface Texture: Profile Method-Terms, Definitions and Surface Texture Parameters (1997).

22. Gh. L. J. Farrahi, "Surface hardness measurement and microstructural characterization of steel by X-ray diffraction profile analysis,” J. Eng., 8, 159-167 (1995).

23. I. Fernandez Pariente and M. Guagliano, "About the role of residual stresses and surface work hardening on fatigue $K_{t h}$ of a nitrided and shot peened low-alloy steel," Surf. Coat. Technol., 202, No. 13, 3072-3080 (2008).

Received 20. 10. 2014 